\title{
Participation in the Comprehensive Primary Care Plus Initiative
}

Pragya Singh, $P b D$

Sean Orzol, MPH, PbD

Deborab Peikes, MPA, PbD

Eunbae G. Ob, MPP

Stacy Dale, MPA

Mathematica Policy Research, Princeton, New Jersey

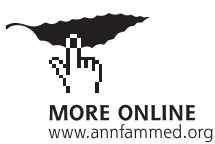

Conflicts of interest: authors report none.

\section{CORRESPONDING AUTHOR}

Pragya Singh

600 Alexander Park, Suite 100

Princeton, NJ 08540

PSingh@mathematica-mpr.com

\begin{abstract}
PURPOSE Comprehensive Primary Care Plus (CPC+) is the largest test of primary care payment and delivery reform. This program aims to strengthen primary care via enhanced and alternative payment, data feedback, learning, and health information technology support for practice transformation for more than 3,000 practices. We analyzed participation rates and how $C P C+$ practices differ from other primary care practices in $C P C+$ regions.
\end{abstract}

METHODS We assembled a unique data set describing all US primary care practices and compared primary care practices in CPC+ regions, CPC+ applicants, and $C P C+$ participants. Among CPC+ participants, we compared across 2 model tracks.

RESULTS Of the primary care practices in CPC+ regions, 22\% applied for CPC+ and $15 \%$ participated. Practices that applied to CPC+ were diverse, but they were generally larger, more sophisticated electronic health record users, more likely to be owned by a hospital or health system, more likely to have experience with transformation efforts, and more likely to be in urban areas than practices that did not apply. Applicants also generally served slightly healthier and more advantaged Medicare fee-for-service beneficiaries. Differences between practices that applied but did not join CPC+ and CPC+ participants were smaller yet systematic.

CONCLUSIONS Participants in CPC+ are diverse but not representative of all primary care practices, underscoring the need to further engage practices that are small, independent, in rural areas, and lack experience with practice and payment transformation models, as well as the need to extrapolate evaluation results carefully.

Ann Fam Med 2020;18:309-317. https://doi.org/10.1370/afm.2544.

\section{INTRODUCTION}

I $\mathrm{n}$ the rapidly changing health care landscape, Medicare and other insurers increasingly expect practitioners to transform how they deliver care and to shift toward value-based reimbursement. Assessment of the rate of participation in transformation models and the characteristics of practices that volunteer to participate can help payers identify potential markers of practices' willingness to assume the responsibilities and requirements for transformation. These measures can also help identify implications for generalizing findings when applied to more typical practices and ways to prevent some types of practices from being left behind in the move to improve care delivery and shift to value-based payment.

We examined participation in the Comprehensive Primary Care Plus (CPC+) initiative, which is the largest voluntary primary care payment and delivery reform model tested to date. ${ }^{1}$ It requires practices in 18 regions to improve how they deliver primary care, supported by enhanced and alternative payments, performance feedback, and learning supports. The CPC+ initiative includes 2 transformation tracks for practices. Track 2 practices receive more supports and are required to provide more enhanced care delivery capabilities to better support patients with more complex needs compared with Track 1 practices (see Supplemental 
Appendix, https://www.AnnFamMed.org/content/18/4/309/supp1/DC1 for details on the model).

We found only 1 study (Fraze et al, 2018) that examined participation patterns in a primary care initative. ${ }^{2}$ That study compared hospital service areas with and without primary care practices participating in $\mathrm{CPC}+$ in 14 of the $18 \mathrm{CPC}+$ regions. We aimed to expand the understanding of $\mathrm{CPC}+$ participation patterns by covering more practice, market, and Medicare fee-for-service (FFS) beneficiary characteristics. We constructed a rich and unique data set by linking a roster of all US primary care practices with practice and market characteristic data from multiple sources and assembling the characteristics of each practice's attributed Medicare FFS beneficiaries using Medicare enrollment and claims data. We aimed to better capture who participates in $\mathrm{CPC}+$ by covering all $18 \mathrm{CPC}+$ regions, not just the 14 that began participating in 2017. This includes 3,051 practices that were participating in $\mathrm{CPC}+$ at the end of their first quarter (Fraze et al included 2,647 of these practices). ${ }^{2}$ We also wanted to compare participation by track to examine the influence of the stricter eligibility criteria, model requirements, and greater payment for participation in Track 2.

\section{METHODS}

\section{Setting and Study Sample}

The study sample comprised practices that did not apply, did apply, and participated in CPC+ in $18 \mathrm{CPC}+$ regions. Regions were selected by the Centers for Medicare and Medicaid Services (CMS) to participate in $\mathrm{CPC}+$ on the basis of market penetration and alignment of interested payers' goals and approaches with CMS' goals and approaches for CPC+. Practice selection criteria included a minimum of 125 attributed Medicare beneficiaries, use of certified health information technology, and use of some advanced care delivery approaches (Supplemental Appendix).

\section{Data Sources}

We assembled a rich and unique data set for the $\mathrm{CPC}+$ evaluation that enabled us to compare participation patterns among primary care practices in the 18 regions using the following 3 types of measures: (1) practice characteristics such as counts of total and primary care practitioners, ownership status (hospital-or system-owned/independent), and indicators of whether the practice participated in certain prior transformation initiatives ( $_{i}$ (2) characteristics, such as rural/urban/suburban status and median household income, of the county in which the practice is located; and (3) characteristics, such as demographics (age, sex, race), hierarchical condition category (HCC) scores (a measure of risk for subsequent expenditures), expenditures, and utilization (acute hospitalizations, emergency department visits), of the Medicare FFS beneficiaries served by the practice.

To assemble these data, we began with the $\mathrm{SK} \& \mathrm{~A}$ office-based physician database (IQVIA) (Fraze et al used a different database from the same vendor, the SK\&A Health Care Organization Services data). 2,3 The study roster included all US practices with $\geq 1$ practitioner (defined as a physician, nurse practitioner, or physician assistant) with a primary care specialty (defined as family practice, general practice, geriatrics, or internal medicine), the practitioners who work at each practice site, and their National Provider Identifiers.

We then identified $\mathrm{CPC}+$ practices in the roster by matching practice name and/or address and by National Provider Identifiers listed in CPC+ application data (we did not require all information to match). We were able to link approximately $95 \%$ of the $\mathrm{CPC}+$ practices to a practice in the $\mathrm{SK} \& \mathrm{~A}$ data. For the remaining $\mathrm{CPC}+$ practices, we added $\mathrm{CPC}+$ application data to ensure that we had the full sample of CPC+ practices at the start of CPC+. These data included practice name, practice characteristics, and affiliated providers.

Next, we added practice and market characteristics, including publicly available data (eg, Area Resource File), CMS restricted-use data (eg, Master Data Management), and proprietary data (eg, National Committee for Quality Assurance data), from multiple sources (described in Supplemental Table 1). To assess the characteristics of each practice's Medicare FFS beneficiary patients, we used Medicare claims and enrollment data to assign beneficiaries to the primary care practice where they received the greatest share of their primary care. All characteristics were measured using the most recent data available before $\mathrm{CPC}+$ began, so they were not affected by CPC+. Practices in 14 regions began CPC+ on January 1, 2017, and practices in the remaining 4 regions began on January 1, 2018. The Supplemental Appendix provides additional details on assignment and data set construction. All data processing to construct the analytic file used in this study were performed using SAS (SAS Institute, Inc).

We calculated participation rates using the set of primary care practices identified using the SK\&A roster and CPC+ application data. However, to compare characteristics across $\mathrm{CPC}+$ participants-overall and by track, CPC+ applicants, and nonapplicants-we restricted the analysis to the 16,883 practices in the 18 $\mathrm{CPC}+$ regions with attributed Medicare beneficiaries. Supplemental Table 2 (https://www.AnnFamMed.org/ content/18/4/309/suppl/DC1) details why practices 
might not have attributed Medicare FFS beneficiaries and the number of such practices in each group.

The New England Independent Institutional Review Board granted the evaluation of CPC+ an exemption on the basis of the federal common rule (section 45 CFR 46.101[b][5]) because the purpose of the study was to evaluate a public benefit program.

\section{Statistical Analysis}

We analyzed characteristics of each practice, its county, and its Medicare beneficiaries in the $18 \mathrm{CPC}+$ regions and made 3 types of comparisons between (1) applicants and nonapplicants, (2) participants and nonparticipants among applicants, and (3) participants in the $2 \mathrm{CPC}+$ tracks. For continuous variables, we reported descriptive statistics using (1) means with 95\% CIs of the practice-level averages, or (2) for skewed data, medians of the practice-level averages with interquartile ranges. For categorical variables, we used percentages. We used 2-tailed $t$ tests or Wilcoxon rank sum tests, as appropriate, to calculate statistical significance of differences. We used a significance level of .05. All statistical analyses were conducted using Stata, version 15 (StataCorp, LLC).

\section{RESULTS}

\section{Participation Rates}

Of the 19,809 practices identified providing primary care to adults in the 18 regions, 4,366 (22\%) applied to participate in CPC+ (233 additional applicant practices could not be identified in our data). All 3,051 practices that met minimum requirements, or $15 \%$ of the 19,809 , were accepted by CMS.

Participation rates varied across the 18 regions (Supplemental Table 3, https://www.AnnFamMed.org/ content/18/4/309/suppl/DC1). Four regions had participation rates of $2 \%$ to $10 \%, 8$ had rates from $11 \%$ to $20 \%$, and the remaining 6 regions had rates from $21 \%$ to $34 \%$.

Tables 1 to 4 and Supplemental Tables 4 and 5 (https://www.AnnFamMed.org/content/18/4/309/suppl/ DC1) show comparisons of practice characteristics between (1) applicants and nonapplicants among practices in the CPC+ regions, (2) participants and nonparticipants among CPC+ applicants, and (3) Track 1 and Track 2 participants.

\section{CPC+ Participants}

Practices participating in $\mathrm{CPC}+$ were not representative of the practices in the 18 regions, but they were still diverse. A total of $27 \%$ of the $\mathrm{CPC}+$ practices were large ( $>6$ primary care practitioners), 37\% were medium (3-5 primary care practitioners), and $36 \%$ were small (1-2 primary care practitioners) (Table 3 ). Nearly one-half of the practices were independent $(46 \%)$, and the remaining $54 \%$ were owned by a health system or a hospital. A total of $61 \%$ of CPC+ practices had primary care transformation experience (that is, they had patient-centered medical home recognition or had participated in the Multi-Payer Advanced Primary Care Practice demonstration or the CPC Classic initiative), and $46 \%$ were participating in a Medicare Shared Savings Program (SSP) Accountable Care Organization (ACO) at the start of CPC+. A total of $85 \%$ had primary care transformation experience or had been in the Transforming Clinical Practice Initiative (TCPI) or SSP. Participating practices also served a diverse set of patients, as measured by their demographic data (age, sex, race) and HCC scores (Table 4).

\section{CPC+ Applicants vs Nonapplicants in CPC+ Regions}

There were large differences between applicant and nonapplicant primary care practices in terms of size, meaningful use of electronic health records (EHRs), hospital ownership, and transformation experience (Table 1). Practices that applied to CPC+ were larger in size (both in the median number of attributed Medicare FFS beneficiaries [410 vs 155 ] and in the median number of practitioners of any specialty [3.0 vs 2.0$]$ ), more sophisticated EHR users ( $86 \%$ had $\geq 1$ practitioner who had attested to meaningful use of EHRs vs $48 \%$ for nonapplicants), more likely to be owned by a hospital or health system (51\% vs $25 \%$ ), and more likely to have had experience with transformation efforts before CPC+ $(54 \%$ vs $16 \%$ had primary care transformation experience, $47 \%$ vs $25 \%$ were participating in a Medicare SSP ACO, and $81 \%$ vs $40 \%$ had primary care transformation experience or had been in TCPI or SSP) compared to practices that did not apply.

There were small differences in the counties of practices that did and did not apply. Applicants were less likely to be located in rural areas ( $9 \%$ vs $14 \%$ ), and their counties had slightly greater median household income $(\$ 53,164$ vs $\$ 50,453)$ compared to nonapplicants (Table 1).

Applicants served slightly healthier and more advantaged Medicare FFS beneficiaries than practices that did not apply. For example, beneficiaries who were dually eligible for Medicare and Medicaid constituted a smaller percentage of the patient population among applicant than nonapplicant practices (17\% vs $23 \%)$ (Table 2). Applicants also served a smaller percentage of black beneficiaries (9\% vs 13\%) and beneficiaries belonging to other nonwhite and nonblack races (7\% vs $8 \%$ ) than nonapplicants. The mean HCC score among beneficiaries served by applicant practices was 
Table 1. Practice Characteristics of CPC+ Applicants and Nonapplicants in CPC+ Regions, Before CPC+

\begin{tabular}{|c|c|c|c|c|}
\hline \multirow[b]{2}{*}{ Characteristic } & \multirow[b]{2}{*}{$\begin{array}{l}\text { All Practices } \\
(\mathrm{n}=16,883)^{\mathrm{a}}\end{array}$} & \multicolumn{2}{|c|}{$\begin{array}{l}\text { Among All Practices } \\
\text { in CPC+ Regions }\end{array}$} & \multirow[b]{2}{*}{$\begin{array}{c}P \\
\text { Value }\end{array}$} \\
\hline & & $\begin{array}{l}\text { Applicants } \\
(\mathrm{n}=4,346)^{\mathrm{b}}\end{array}$ & $\begin{array}{l}\text { Nonapplicants } \\
(\mathrm{n}=12,537)\end{array}$ & \\
\hline \multicolumn{5}{|l|}{ Practice size and ownership at baseline ${ }^{c}$} \\
\hline Total no. of practitioners (any specialty), median (IQR) & $2.0(1.0-4.0)$ & $3.0(2.0-6.0)$ & $2.0(1.0-3.0)$ & $<.001$ \\
\hline No. of primary care practitioners, median (IQR) & $2.0(1.0-3.0)$ & $3.0(2.0-5.0)$ & $1.0(1.0-3.0)$ & $<.001$ \\
\hline \multicolumn{5}{|l|}{ Practice size } \\
\hline Large (> 6 primary care practitioners), \% (95\% Cl) & $12.0(11.5-12.5)$ & $23.2(22.0-24.5)$ & $8.1(7.6-8.6)$ & $<.001$ \\
\hline Medium (3-5 primary care practitioners), $\%(95 \% \mathrm{Cl})$ & $24.6(23.9-25.2)$ & $36.2(34.8-37.6)$ & $20.5(19.8-21.2)$ & $<.001$ \\
\hline Small (1-2 primary care practitioners), \% (95\% Cl) & $63.4(62.7-64.2)$ & $40.5(39.1-42.0)$ & $71.4(70.6-72.2)$ & $<.001$ \\
\hline $\begin{array}{l}\text { No. of attributed Medicare FFS beneficiaries at baseline, } \\
\text { median (IQR) }\end{array}$ & $204(82-412)$ & $410(231-740)$ & $155(55-311)$ & $<.001$ \\
\hline $\begin{array}{l}\text { No. of attributed Medicare FFS beneficiaries at baseline } \\
\text { per PCP, median (IQR) }\end{array}$ & $113(48-194)$ & $144(89-214)$ & $99(32-183)$ & $<.001$ \\
\hline Owned by a health system or hospital, $\%(95 \% \mathrm{Cl})^{\mathrm{d}}$ & $31.6(30.9-32.3)$ & $50.9(49.5-52.4)$ & $24.9(24.2-25.7)$ & $<.001$ \\
\hline Owned or managed by a health system, \% ( $95 \% \mathrm{Cl})$ & $27.2(26.5-27.8)$ & $46.4(44.9-47.8)$ & $20.5(19.8-21.2)$ & $<.001$ \\
\hline Owned by a hospital, \% (95\% Cl) & $17.4(16.8-18.0)$ & $25.4(24.1-26.7)$ & $14.7(14.0-15.3)$ & $<.001$ \\
\hline \multicolumn{5}{|l|}{ Practices with selected transformation experience } \\
\hline PCMH recognition, \% $(95 \% \mathrm{Cl})^{\mathrm{e}}$ & $23.8(23.1-24.4)$ & $47.5(46.0-49.0)$ & $15.5(14.9-16.2)$ & $<.001$ \\
\hline $\begin{array}{l}\text { Participant in a Medicare SSP ACO as of January } 1 \text { of the } \\
\text { first intervention year, \% ( } 95 \% \text { CI) }\end{array}$ & $31.0(30.3-31.7)$ & $47.0(45.6-48.5)$ & $25.4(24.6-26.2)$ & $<.001$ \\
\hline Participant in CMMI's TCPI, \% (95\% Cl) & $7.6(7.2-8.0)$ & $10.5(9.6-11.4)$ & $6.6(6.2-7.1)$ & $<.001$ \\
\hline Participant in CMMI's MAPCP, \% $(95 \% \mathrm{Cl})^{\mathrm{f}}$ & $2.5(2.3-2.7)$ & $5.6(4.9-6.3)$ & $1.4(1.2-1.7)$ & $<.001$ \\
\hline Participant in CPC Classic, \% $(95 \% \text { Cl })^{g}$ & $2.6(2.3-2.8)$ & $9.9(9.1-10.8)$ & $0(0-0)$ & $<.001$ \\
\hline $\begin{array}{l}\text { Primary care transformation experience (PCMH recognitione, } \\
\text { MAPCPf, or CPC Classicg), \% }(95 \% \mathrm{Cl})\end{array}$ & $25.8(25.2-26.5)$ & $53.6(52.1-55.1)$ & $16.2(15.6-16.8)$ & $<.001$ \\
\hline Primary care transformation experience or TCPI, \% $(95 \% \mathrm{Cl})$ & $31.3(30.6-32.0)$ & $59.4(58.0-60.9)$ & $21.6(20.8-22.3)$ & $<.001$ \\
\hline $\begin{array}{l}\text { Primary care transformation experience or TCPI or SSP as of } \\
\text { January } 1 \text { of the first intervention year, } \%(95 \% \mathrm{CI})\end{array}$ & $50.5(49.8-51.3)$ & $81.1(79.9-82.3)$ & $39.9(39.1-40.8)$ & $<.001$ \\
\hline $\begin{array}{l}\text { Practices with } \geq 1 \text { practitioner attesting to meaningful } \\
\text { use of EHRs, } \%(95 \% \mathrm{Cl})^{\mathrm{h}}\end{array}$ & $57.7(57.0-58.4)$ & $85.8(84.7-86.8)$ & $48.0(47.1-48.9)$ & $<.001$ \\
\hline \multicolumn{5}{|l|}{ Characteristics of practice county } \\
\hline $\begin{array}{l}\text { Household income in county in which practice is located }(\$) \text {, } \\
\text { median (IQR)i }\end{array}$ & $\begin{array}{c}51,475 \\
(43,338-62,867)\end{array}$ & $\begin{array}{c}53,164 \\
(45,698-64,916)\end{array}$ & $\begin{array}{c}50,453 \\
(42,896-62,861)\end{array}$ & $<.001$ \\
\hline Rural location, \% (95\% Cl) & $12.9(12.4-13.4)$ & $8.6(7.7-9.4)$ & $14.4(13.8-15.0)$ & $<.001$ \\
\hline Suburban location, \% $(95 \% \mathrm{CI})^{\mathrm{j}}$ & $14.5(14.0-15.0)$ & $14.8(13.8-15.9)$ & $14.4(13.8-15.0)$ & .469 \\
\hline Urban location, \% $(95 \% \mathrm{Cl})^{j}$ & $72.6(71.9-73.2)$ & $76.6(75.3-77.9)$ & $71.2(70.472 .0)$ & $<.001$ \\
\hline
\end{tabular}

AAAHC = Accreditation Association for Ambulatory Health Care; ACO = Accountable Care Organization; CMMI = Center for Medicare and Medicaid Innovation; CMS = Centers for Medicare and Medicaid Services; $C P C=$ Comprehensive Primary Care; $C P C+=$ Comprehensive Primary Care Plus; EHR = electronic health record; FFS = fee for service; $\mathrm{IQR}=$ interquartile range; MAPCP = Multi-Payer Advanced Primary Care Practice; NCQA = National Committee for Quality Assurance; $\mathrm{PCMH}=$ patient-centered medical home; $\mathrm{PCP}=$ primary care practitioner; SSP = Shared Savings Program; $\mathrm{TCPI}=$ Transforming Clinical Practice Initiative; $\mathrm{TJC}=\mathrm{The}$ Joint Commission; URAC = Utilization Review Accreditation Commission

Note: Table presents the unweighted mean value for each characteristic. Primary care practices include all practices with $\geq 1$ practitioner (defined as a physician, nurse practitioner, or physician assistant) with a specialty of primary care (defined as family practice, general practice, geriatrics, or internal medicine). The 2018 starters represent $11 \%$ of all practices, $7 \%$ of applicants, and $5 \%$ of participants.

Sources: Mathematica's analysis of data on practice size and ownership from SKEA data; data on the number and characteristics of attributed Medicare beneficiaries from Medicare Enrollment Database and claims data; data on PCMH recognition from NCQA, TJC, AAAHC, URAC, and state-specific data sources; data on Medicare SSP ACO participation from CMS Master Data Management data; data on participation in CMMI's TCPI, CMMI's MAPCP, and CPC Classic from CMS; data on meaningful use of EHRs from CMS Medicare EHR Incentive Program; county data from the Area Resource File.

a Table includes 16,883 of the 19,809 primary care practices in the 2017 and 2018 regions because we excluded 2,926 practices (15\%) that had no attributed Medicare FFS beneficiaries in the baseline year.

${ }^{\mathrm{b}}$ A total of 4,599 practices applied for CPC+. The number of applicants in this table $(4,346)$ is fewer because some applicants could not be identified in the SKEA data, and some applicants had no attributed Medicare FFS beneficiaries at baseline.

' The baseline year is 2016 for the 2017 starters and 2017 for the 2018 starters.

d In the SKEA data, a practice can be owned (or managed) by a health system and owned by a hospital.

e A practice was considered to have PCMH recognition if $\geq 1$ of its primary care practitioners had recognition at some point in $2014-2017$ for the 2017 starters and 2015-2018 for the 2018 starters from a state, the AAAHC, TJC, NCQA, or URAC.

'We considered a practice to be a MAPCP participant if it participated in any year from 2011-2014, as determined by a file from CMS.

g Participants include all those practices that stayed enrolled in CPC Classic for at least the first 5 months.

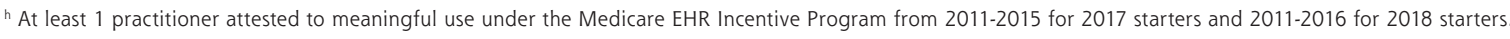
Reflects 2014 data for the 2017 starters and 2015 data for the 2018 starters.

j The urbanicity of a practice's county (rural, urban, suburban) is derived from the 2013 (latest year available) rural-urban continuum codes (https://www.ers.usda.gov/ data-products/rural-urban-continuum-codes/documentation/) available in the Area Resource Files for both 2017 and 2018 starters. 


\section{Among All Practices}

in CPC+ Regions

\begin{tabular}{|c|c|c|c|c|}
\hline Characteristic & $\begin{array}{l}\text { All Practices } \\
(n=16,883)^{a}\end{array}$ & $\begin{array}{l}\text { Applicants } \\
(\mathrm{n}=4,346)^{\mathrm{b}}\end{array}$ & $\begin{array}{l}\text { Nonapplicants } \\
(\mathrm{n}=12,537)\end{array}$ & $\begin{array}{c}P \\
\text { Value }\end{array}$ \\
\hline \multicolumn{5}{|l|}{$\begin{array}{l}\text { Characteristics of Medicare FFS beneficiaries } \\
\text { attributed to practice at baseline }\end{array}$} \\
\hline \multicolumn{5}{|l|}{ Age } \\
\hline $0-49$ y, \% (95\% Cl) & $7.4(7.2-7.5)$ & $6.0(5.8-6.2)$ & $7.8(7.6-8.0)$ & $<.001$ \\
\hline $50-64$ y, \% (95\% Cl) & $15.2(15.1-15.5)$ & $13.1(12.9-13.4)$ & $16.0(15.8-16.3)$ & $<.001$ \\
\hline $65-74$ y, \% $(95 \% \mathrm{Cl})$ & $43.6(43.4-43.8)$ & $45.3(45.0-45.6)$ & $43.0(42.8-43.3)$ & $<.001$ \\
\hline $75-84$ y, \% (95\% Cl) & $22.8(22.6-22.9)$ & $24.1(23.9-24.3)$ & $22.3(22.1-22.5)$ & $<.001$ \\
\hline$\geq 85$ y, \% (95\% Cl) & $11.0(10.8-11.1)$ & $11.5(11.3-11.7)$ & $10.8(10.6-11.0)$ & $<.001$ \\
\hline Male, \% $(95 \% \mathrm{Cl})$ & $42.4(42.2-42.6)$ & $41.6(41.4-41.9)$ & $42.7(42.4-42.9)$ & $<.001$ \\
\hline \multicolumn{5}{|l|}{ Race } \\
\hline Black, \% $(95 \%$ Cl) & $12.0(11.7-12.3)$ & $8.5(8.1-9.0)$ & $13.2(12.9-13.6)$ & $<.001$ \\
\hline White, \% (95\% Cl) & $80.1(79.7-80.5)$ & $84.3(83.7-84.9)$ & $78.6(78.2-79.1)$ & $<.001$ \\
\hline Other, \% (95\% Cl) & $7.9(7.6-8.1)$ & $7.2(6.8-7.6)$ & $8.1(7.8-8.4)$ & $<.001$ \\
\hline Dually eligible for Medicare and Medicaid, \% $(95 \% \mathrm{Cl})^{d}$ & $21.7(21.4-22.0)$ & $17.0(16.6-17.5)$ & $23.4(23.0-23.8)$ & $<.001$ \\
\hline $\mathrm{HCC}$ score attributed in baseline year, mean $(95 \% \mathrm{Cl})^{\mathrm{e}}$ & $1.15(1.15-1.16)$ & $1.12(1.11-1.13)$ & $1.16(1.16-1.17)$ & $<.001$ \\
\hline \multicolumn{5}{|l|}{ Chronic conditions as of baseline year ${ }^{f}$} \\
\hline Alzheimer disease and related dementia, \% (95\% Cl) & $8.3(8.1-8.4)$ & $7.7(7.5-7.9)$ & $8.4(8.3-8.6)$ & $<.001$ \\
\hline Cancer, \% $(95 \% \mathrm{Cl})$ & $7.0(7.0-7.1)$ & $7.6(7.5-7.7)$ & $6.8(6.7-6.9)$ & $<.001$ \\
\hline Chronic obstructive pulmonary disease, \% (95\% Cl) & $11.5(11.4-11.7)$ & $10.8(10.7-11.0)$ & $11.8(11.6-12.0)$ & $<.001$ \\
\hline Chronic kidney disease, \% (95\% Cl) & $16.9(16.7-17.1)$ & $16.8(16.6-17.1)$ & $16.9(16.7-17.1)$ & .665 \\
\hline Congestive heart failure, \% (95\% Cl) & $12.7(12.5-12.8)$ & $11.4(11.2-11.6)$ & $13.1(12.9-13.3)$ & $<.001$ \\
\hline Diabetes, \% (95\% Cl) & $27.9(27.7-28.1)$ & $26.3(26.1-26.6)$ & $28.4(28.2-28.7)$ & $<.001$ \\
\hline \multicolumn{5}{|l|}{$\begin{array}{l}\text { Medicare FFS expenditures and service use for Medicare } \\
\text { FFS beneficiaries attributed to practice at baseline }\end{array}$} \\
\hline $\begin{array}{l}\text { Medicare expenditures per beneficiary }(\$ / m o) \text {, } \\
\text { median }(\mathrm{IQR})^{\mathrm{g}, \mathrm{h}}\end{array}$ & $878(717-1,088)$ & $858(744-1,004)$ & $888(702-1,126)$ & $<.001$ \\
\hline $\begin{array}{l}\text { Weighted Medicare expenditures per beneficiary ( } \$ / \mathrm{mo}) \text {, } \\
\text { median (IQR) }\end{array}$ & $875(765-1,020)$ & $855(761-976)$ & $895(771-1,067)$ & $<.001$ \\
\hline $\begin{array}{l}\text { Acute care stays per 1,000 beneficiaries (annualized), } \\
\text { median (IQR) }\end{array}$ & $289(220-374)$ & $282(233-346)$ & $292(213-388)$ & .007 \\
\hline ED visits per 1,000 beneficiaries (annualized), median (IQR) & $506(368-721)$ & $481(374-638)$ & $518(364-762)$ & $<.001$ \\
\hline $\begin{array}{l}\text { Primary care (ambulatory) visits per 1,000 beneficiaries } \\
\text { (annualized), median (IQR) }\end{array}$ & $4,518(3,724-5,517)$ & $4,471(3,927-5,161)$ & $4,539(3,623-5,683)$ & .592 \\
\hline $\begin{array}{l}\text { Percentage of discharges for which beneficiary had a 14-day } \\
\text { follow-up visit after hospitalization, median (IQR) }\end{array}$ & $67.6(59.6-74.8)$ & $69.1(63.0-74.4)$ & $66.7(57.7-75.0)$ & $<.001$ \\
\hline
\end{tabular}

CMS = Centers for Medicare and Medicaid Services; $C P C+=$ Comprehensive Primary Care Plus; $E D=$ emergency department; $F F S=$ fee for service; $H C C=$ hierarchical condition category; IQR = interquartile range.

Note: Primary care practices include all practices with $\geq 1$ practitioner (defined as a physician, nurse practitioner, or physician assistant) with a specialty of primary care (defined as family practice, general practice, geriatrics, or internal medicine). The 2018 starters represent $11 \%$ of all practices, $7 \%$ of applicants, and $5 \%$ of participants.

Sources: Mathematica's analysis of data on the number, characteristics, and service use and spending of attributed Medicare beneficiaries based on Medicare Enrollment Database and claims data.

a Table includes 16,883 of the 19,809 primary care practices in the 2017 and 2018 regions because we excluded 2,926 practices (15\%) that had no attributed Medicare FFS beneficiaries in the baseline year.

b A total of 4.599 practices applied for CPC+. The number of applicants in this table $(4,346)$ is fewer because some applicants could not be identified in the SKEA data, and some applicants had no attributed Medicare FFS beneficiaries at baseline.

c The baseline year is 2016 for the 2017 starters and 2017 for the 2018 starters.

${ }^{d}$ Calculated as the percentage of beneficiaries attributed to a practice in the baseline year who were dually eligible for Medicare and Medicaid in the quarter before the start of the baseline year.

e The HCC score is based on beneficiaries' diagnoses in 2015 (for 2017 starters) or 2016 (for 2018 starters).

${ }^{\mathrm{f}}$ The lookback periods for the chronic conditions are 3 years before the baseline year for Alzheimer and related dementia, 1 year before the baseline year for cancer and chronic obstructive pulmonary disease, and 2 years before the baseline year for chronic kidney disease, congestive heart failure, and diabetes.

g We deflated the 2017 (baseline) mean and median per beneficiary per month expenditures for the practices in the 2018 CPC+ regions by the $0.9 \%$ Medicare inflation rate (CMS Office of the Actuary, personal communication, May 6, 2019).

${ }^{\mathrm{h}}$ For the calculation of the weighted (mean/median) monthly Medicare expenditures per beneficiary, the practice-level expenditure variable (mean/median) is weighted by the number of beneficiaries attributed to the practice, so that practices with more attributed beneficiaries get a greater weight. The means and medians for all of the other characteristics in the table are unweighted, meaning that each practice is treated equally, regardless of its size.

i This measure was calculated for beneficiaries attributed in the first quarter of the baseline year. 
Table 3. Practice Characteristics of CPC+ Participants and Nonparticipants Among CPC+ Applicants, Before CPC+

Among Applicants

\begin{tabular}{|c|c|c|c|c|}
\hline Characteristic & $\begin{array}{l}\text { Applicants } \\
(\mathrm{n}=4,346)^{\mathrm{a}}\end{array}$ & $\begin{array}{l}\text { Participants } \\
(\mathrm{n}=3,051)^{\mathrm{b}, \mathrm{c}}\end{array}$ & $\begin{array}{l}\text { Nonparticipants } \\
\quad(n=1,295)\end{array}$ & $\begin{array}{c}P \\
\text { Value }\end{array}$ \\
\hline \multicolumn{5}{|l|}{ Practice size and ownership at baseline ${ }^{d}$} \\
\hline Total no. of practitioners (any specialty), median (IQR) & $3.0(2.0-6.0)$ & $4.0(2.0-6.0)$ & $3.0(2.0-5.0)$ & $<.001$ \\
\hline No. of primary care practitioners, median (IQR) & $3.0(2.0-5.0)$ & $3.0(2.0-6.0)$ & $2.0(1.0-4.0)$ & $<.001$ \\
\hline \multicolumn{5}{|l|}{ Practice size } \\
\hline Large (> 6 primary care practitioners), \% (95\% Cl) & $23.3(22.0-24.5)$ & $26.6(25.0-28.2)$ & $15.4(13.4-17.3)$ & $<.001$ \\
\hline Medium (3-5 primary care practitioners), $\%$ (95\% Cl) & $36.2(34.8-37.6)$ & $37.1(35.4-38.9)$ & $34.1(31.5-36.6)$ & .052 \\
\hline Small (1-2 primary care practitioners), \% (95\% Cl) & $40.5(39.1-42.0)$ & $36.3(34.5-38.0)$ & $50.6(47.9-53.3)$ & $<.001$ \\
\hline $\begin{array}{l}\text { No. of attributed Medicare FFS beneficiaries at baseline, } \\
\text { median (IQR) }\end{array}$ & $410(231-740)$ & $484(288-837)$ & $253(117-497)$ & $<.001$ \\
\hline $\begin{array}{l}\text { No. of attributed Medicare FFS beneficiaries at baseline per } \\
\text { PCP, median (IQR) }\end{array}$ & $144(89-214)$ & $159(107-232)$ & $107(61-173)$ & $<.001$ \\
\hline Owned by a health system or hospital, \% $(95 \% \mathrm{Cl})^{\mathrm{e}}$ & $50.9(49.5-52.4)$ & $54.0(52.2-55.8)$ & $43.7(41.0-46.4)$ & $<.001$ \\
\hline Owned or managed by a health system, \% ( $95 \%$ Cl) & $46.4(44.9-47.8)$ & $49.3(47.5-51.0)$ & $39.5(36.9-42.2)$ & $<.001$ \\
\hline Owned by a hospital, \% (95\% Cl) & $25.4(24.1-26.7)$ & $27.6(26.0-29.2)$ & $20.2(18.0-22.4)$ & $<.001$ \\
\hline \multicolumn{5}{|l|}{ Practices with selected transformation experience } \\
\hline PCMH recognition, \% $(95 \% \mathrm{Cl})^{4}$ & $47.5(46.0-49.0)$ & $52.6(50.8-54.3)$ & $35.4(32.8-38.1)$ & $<.001$ \\
\hline $\begin{array}{l}\text { Participant in a Medicare SSP ACO as of January } 1 \text { of the first } \\
\text { intervention year, } \%(95 \% \mathrm{CI})\end{array}$ & $47.0(45.6-48.5)$ & $46.2(44.5-48.0)$ & $49.0(46.2-51.7)$ & .104 \\
\hline Participant in CMMI's TCPI, \% (95\% Cl) & $10.5(9.6-11.4)$ & $10.8(9.7-11.9)$ & $9.7(8.1-11.3)$ & .276 \\
\hline Participant in CMMI's MAPCP, \% $(95 \% \mathrm{Cl})^{g}$ & $5.6(4.9-6.3)$ & $6.9(6.0-7.7)$ & $2.5(1.7-3.4)$ & $<.001$ \\
\hline Participant in CPC Classic, \% $(95 \% \mathrm{Cl})^{\mathrm{h}}$ & $9.9(9.1-10.8)$ & $14.1(12.8-15.3)$ & $0.2(0-0.5)$ & $<.001$ \\
\hline $\begin{array}{l}\text { Primary care transformation experience (PCMH recognition }{ }^{f} \\
\text { MAPCPg, or CPC Classich), } \%(95 \% \mathrm{Cl})\end{array}$ & $53.6(52.1-55.1)$ & $60.7(59.0-62.4)$ & $36.8(34.2-39.5)$ & $<.001$ \\
\hline Primary care transformation experience or TCPI, \% (95\% Cl) & $59.4(58.0-60.9)$ & $65.7(64.1-67.4)$ & $44.5(41.8-47.2)$ & $<.001$ \\
\hline $\begin{array}{l}\text { Primary care transformation experience or TCPI or SSP as of } \\
\text { January } 1 \text { of the first intervention year, } \%(95 \% \mathrm{Cl})\end{array}$ & $81.1(79.9-82.3)$ & $84.6(83.3-85.9)$ & $72.9(70.5-75.3)$ & $<.001$ \\
\hline $\begin{array}{l}\text { Practices with } \geq 1 \text { practitioner attesting to meaningful } \\
\text { use of EHRs, } \%(95 \% \mathrm{Cl})^{i}\end{array}$ & $85.8(84.7-86.8)$ & $90.4(89.3-91.4)$ & $74.9(72.5-77.3)$ & $<.001$ \\
\hline \multicolumn{5}{|l|}{ Characteristics of practice county } \\
\hline $\begin{array}{l}\text { Household income in county in which practice is located (\$), } \\
\text { median (IQR)j }\end{array}$ & $\begin{array}{c}53,164 \\
(45,698-64,916)\end{array}$ & $\begin{array}{c}54,089 \\
(46,185-66,315)\end{array}$ & $\begin{array}{c}49,503 \\
(44,015-61,170)\end{array}$ & $<.001$ \\
\hline Rural location, \% $(95 \% \mathrm{Cl})^{\mathrm{k}}$ & $8.6(7.7-9.4)$ & $8.7(7.7-9.7)$ & $8.3(6.8-9.8)$ & .646 \\
\hline Suburban location, $\%(95 \% \mathrm{Cl})^{\mathrm{k}}$ & $14.8(13.8-15.9)$ & $15.4(14.2-16.7)$ & $13.4(11.6-15.3)$ & .082 \\
\hline Urban location, \% $(95 \% \mathrm{Cl})^{\mathrm{k}}$ & $76.6(75.3-77.9)$ & $75.9(74.4-77.4)$ & $78.3(76.1-80.5)$ & .08 \\
\hline
\end{tabular}

$\mathrm{AAAHC}=$ Accreditation Association for Ambulatory Health Care; ACO = Accountable Care Organization; CMMI = Center for Medicare and Medicaid Innovation; CMS = Centers for Medicare and Medicaid Services; CPC = Comprehensive Primary Care; CPC+ = Comprehensive Primary Care Plus; EHR = electronic health record; FFS = fee for service; $I Q R=$ interquartile range; $M A P C P=$ Multi-Payer Advanced Primary Care Practice; NCQA = National Committee for Quality Assurance; $\mathrm{PCMH}=$ patient-centered medical home; $\mathrm{PCP}=$ primary care practitioner; $\mathrm{SSP}=$ Shared Savings Program; $\mathrm{TCPI}=$ Transforming Clinical Practice Initiative; $\mathrm{TJC}=\mathrm{The}$ Joint Commission; URAC = Utilization Review Accreditation Commission

Note: Table presents the unweighted mean value for each characteristic. Primary care practices include all practices with $\geq 1$ practitioner (defined as a physician, nurse practitioner, or physician assistant) with a specialty of primary care (defined as family practice, general practice, geriatrics, or internal medicine). The 2018 starters represent $11 \%$ of all practices, $7 \%$ of applicants, and $5 \%$ of participants.

Sources: Mathematica's analysis of data on practice size and ownership from SKEA data; data on the number and characteristics of attributed Medicare beneficiaries from Medicare Enrollment Database and claims data; data on PCMH recognition from NCQA, TJC, AAAHC, URAC, and state-specific data sources; data on Medicare SSP ACO participation from CMS Master Data Management data; data on participation in CMMI's TCPI, CMMI's MAPCP, and CPC Classic from CMS; data on meaningful use of EHRs from CMS Medicare EHR Incentive Program; county data from the Area Resource File.

a A total of 4,599 practices applied for CPC+. The number of applicants in this table $(4,346)$ is fewer because some applicants could not be identified in the SKEA data, and some applicants had no attributed Medicare FFS beneficiaries at baseline.

b The 2018 starters comprise approximately $5 \%$ of the participating CPC+ practices and 5\% of attributed beneficiaries.

'As of April 1 of the first intervention year.

${ }^{d}$ The baseline year is 2016 for the 2017 starters and 2017 for the 2018 starters.

e In the SKEA data, a practice can be owned (or managed) by a health system and owned by a hospital.

${ }^{\mathrm{f}}$ A practice was considered to have PCMH recognition if $\geq 1$ of its primary care practitioners had recognition at some point in $2014-2017$ for the 2017 starters and 2015-2018 for the 2018 starters from a state, the AAAHC, TJC, NCQA, or URAC.

9 We considered a practice to be a MAPCP participant if it participated in any year from 2011-2014 as determined by a file from CMS.

h Participants include all those practices that remained enrolled in CPC Classic for at least the first 5 months.

At least 1 practitioner attested to meaningful use under the Medicare EHR Incentive Program from 2011-2015 for 2017 starters and $2011-2016$ for 2018 starters. j Reflects 2014 data for the 2017 starters and 2015 data for the 2018 starters.

k The urbanicity of a practice's county (rural, urban, suburban) is derived from the 2013 (latest year available) rural-urban continuum codes (https://www.ers.usda.gov/ data-products/rural-urban-continuum-codes/documentation/) available in the Area Resource Files for both 2017 and 2018 starters. 
Table 4. Characteristics of CPC+ Participants and Nonparticipants Among CPC+ Applicants, Based on Medicare FFS Beneficiary Composition, Before CPC+

Among Applicants

\begin{tabular}{|c|c|c|c|c|}
\hline \multirow[b]{2}{*}{ Characteristic } & \multirow[b]{2}{*}{$\begin{array}{l}\text { Applicants } \\
(\mathrm{n}=4,346)^{\mathrm{a}}\end{array}$} & & \multirow[b]{2}{*}{$\begin{array}{c}P \\
\text { Value }\end{array}$} \\
\hline & & $\begin{array}{l}\text { Participants } \\
(\mathrm{n}=3,051)^{\mathrm{b}, \mathrm{c}}\end{array}$ & $\begin{array}{l}\text { Nonparticipants } \\
(n=1,295)\end{array}$ & \\
\hline \multicolumn{5}{|l|}{$\begin{array}{l}\text { Characteristics of Medicare FFS beneficiaries } \\
\text { attributed to practice at baseline }{ }^{d}\end{array}$} \\
\hline \multicolumn{5}{|l|}{ Age } \\
\hline $0-49$ y, \% $(95 \% \mathrm{Cl})$ & $6.0(5.8-6.2)$ & $5.2(5.1-5.4)$ & $7.9(7.5-8.4)$ & $<.001$ \\
\hline $50-64$ y, \% (95\% Cl) & $13.1(12.9-13.4)$ & $12.0(11.7-12.2)$ & $15.9(15.4-16.4)$ & $<.001$ \\
\hline $65-74$ y, \% $(95 \% \mathrm{Cl})$ & $45.3(45.0-45.6)$ & $46.1(45.8-46.4)$ & $43.3(42.7-44.0)$ & $<.001$ \\
\hline $75-84$ y, \% $(95 \% \mathrm{Cl})$ & $24.1(23.9-24.3)$ & $24.9(24.7-25.1)$ & $22.2(21.7-22.6)$ & $<.001$ \\
\hline$\geq 85$ y, \% $(95 \% \mathrm{Cl})$ & $11.5(11.3-11.7)$ & $11.8(11.6-12.0)$ & $10.7(10.2-11.1)$ & $<.001$ \\
\hline Male, \% (95\% Cl) & $41.6(41.4-41.9)$ & 41.7 (41.4-41.9) & $41.5(41.0-42.1)$ & .664 \\
\hline \multicolumn{5}{|l|}{ Race } \\
\hline Black, \% (95\% Cl) & $8.5(8.1-9.0)$ & $6.9(6.5-7.4)$ & $12.3(11.3-13.4)$ & $<.001$ \\
\hline White, \% (95\% Cl) & $84.3(83.7-84.9)$ & $85.8(85.1-86.5)$ & $80.8(79.6-82.0)$ & $<.001$ \\
\hline Other, \% (95\% Cl) & $7.2(6.8-7.6)$ & $7.3(6.8-7.8)$ & $6.9(6.2-7.6)$ & .383 \\
\hline Dually eligible for Medicare and Medicaid, \% $(95 \% \mathrm{Cl})^{\mathrm{e}}$ & $17.0(16.6-17.5)$ & $14.9(14.4-15.4)$ & $22.0(21.0-23.0)$ & $<.001$ \\
\hline HCC score attributed in baseline year, mean $(95 \% \mathrm{Cl})^{\dagger}$ & $1.12(1.11-1.13)$ & $1.10(1.10-1.11)$ & $1.16(1.14-1.18)$ & $<.001$ \\
\hline \multicolumn{5}{|l|}{ Chronic conditions as of baseline year ${ }^{9}$} \\
\hline Alzheimer disease and related dementia, \% (95\% Cl) & $7.7(7.5-7.9)$ & $7.4(7.2-7.5)$ & $8.4(8.0-8.9)$ & $<.001$ \\
\hline Cancer, \% $(95 \% \mathrm{Cl})$ & $7.6(7.5-7.7)$ & $7.9(7.8-8.0)$ & $7.0(6.8-7.1)$ & $<.001$ \\
\hline Chronic obstructive pulmonary disease, \% (95\% Cl) & $10.8(10.7-11.0)$ & $10.3(10.2-10.5)$ & $12.0(11.6-12.4)$ & $<.001$ \\
\hline Chronic kidney disease, \% (95\% Cl) & $16.8(16.6-17.1)$ & $16.4(16.2-16.6)$ & $17.9(17.4-18.4)$ & $<.001$ \\
\hline Congestive heart failure, \% (95\% Cl) & $11.4(11.2-11.6)$ & $11.0(10.8-11.1)$ & $12.4(11.9-12.8)$ & $<.001$ \\
\hline Diabetes, $\%(95 \% \mathrm{Cl})$ & $26.3(26.1-26.6)$ & $25.7(25.4-26.0)$ & $27.8(27.2-28.4)$ & $<.001$ \\
\hline \multicolumn{5}{|l|}{$\begin{array}{l}\text { Medicare FFS expenditures and service use for Medicare } \\
\text { FFS beneficiaries attributed to practice at baseline }\end{array}$} \\
\hline Medicare expenditures per beneficiary $(\$ / m 0)$, median $(\mathrm{IQR})^{\mathrm{h}, \mathrm{i}}$ & $858(744-1,004)$ & $850(745-981)$ & $874(737-1,090)$ & $<.001$ \\
\hline $\begin{array}{l}\text { Weighted Medicare expenditures per beneficiary }(\$ / m o) \text {, } \\
\text { median }(\mathrm{IQR})^{\mathrm{h}, \mathrm{i}}\end{array}$ & $855(761-976)$ & $849(757-964)$ & $869(768-1,020)$ & $<.001$ \\
\hline $\begin{array}{l}\text { Acute care stays per 1,000 beneficiaries (annualized), } \\
\text { median (IQR) }\end{array}$ & $282(233-346)$ & $276(231-331)$ & $302(239-390)$ & $<.001$ \\
\hline ED visits per 1,000 beneficiaries (annualized), median (IQR) & $481(374-638)$ & $465(366-598)$ & $537(397-753)$ & $<.001$ \\
\hline $\begin{array}{l}\text { Primary care (ambulatory) visits per 1,000 beneficiaries (annu- } \\
\text { alized), median (IQR) }\end{array}$ & $4,471(3,927-5,161)$ & $4,443(3,917-5,087)$ & $4,565(3,957-5,503)$ & $<.001$ \\
\hline $\begin{array}{l}\text { Percentage of discharges for which beneficiary had a 14-day } \\
\text { follow-up visit after hospitalization, median (IQR) }\end{array}$ & $69.1(63.0-74.4)$ & $69.6(64.0-74.5)$ & $67.8(60.4-74.3)$ & $<.001$ \\
\hline
\end{tabular}

CMS = Centers for Medicare and Medicaid Services; $C P C+=$ Comprehensive Primary Care Plus; ED = emergency department; FFS = fee for service; HCC = hierarchical condition category; IQR = interquartile range.

Note: Primary care practices include all practices with $\geq 1$ practitioner (defined as a physician, nurse practitioner, or physician assistant) with a specialty of primary care (defined as family practice, general practice, geriatrics, or internal medicine). The 2018 starters represent $11 \%$ of all practices, $7 \%$ of applicants, and $5 \%$ of participants.

Sources: Mathematica's analysis of data on the number, characteristics, and service use and spending of attributed Medicare beneficiaries based on Medicare Enrollment Database and claims data.

a A total of 4,599 practices applied for CPC+. The number of applicants in this table $(4,346)$ is fewer because some applicants could not be identified in the SKEA data, and some applicants had no attributed Medicare FFS beneficiaries at baseline.

b The 2018 starters comprise approximately $5 \%$ of the participating CPC+ practices and $5 \%$ of attributed beneficiaries.

'As of April 1 of the first intervention year.

d The baseline year is 2016 for the 2017 starters and 2017 for the 2018 starters.

e Calculated as the percentage of beneficiaries attributed to a practice in the baseline year who were dually eligible for Medicare and Medicaid in the quarter before the start of the baseline year.

${ }^{\mathrm{f}}$ The HCC score is based on beneficiaries' diagnoses in 2015 (for 2017 starters) or 2016 (for 2018 starters).

$g$ The lookback periods for the chronic conditions are 3 years before the baseline year for Alzheimer and related dementia, 1 year before the baseline year for cancer and chronic obstructive pulmonary disease, and 2 years before the baseline year for chronic kidney disease, congestive heart failure, and diabetes.

${ }^{h}$ We deflated the 2017 (baseline) mean and median per beneficiary per month expenditures for the practices in the 2018 CPC+ regions by the $0.9 \%$ Medicare inflation rate (CMS Office of the Actuary, personal communication, May 6, 2019).

i For the calculation of the weighted (mean/median) monthly Medicare expenditures per beneficiary, the practice-level expenditure variable (mean/median) is weighted by the number of beneficiaries attributed to the practice, so that practices with more attributed beneficiaries get a greater weight. The means and medians for all of the other characteristics in the table are unweighted, meaning that each practice is treated equally, regardless of its size.

j This measure was calculated for beneficiaries attributed in the first quarter of the baseline year. 
also slightly lower than that for nonapplicants (1.12 vs 1.16). Beneficiaries served by applicant practices had slightly lower median Medicare expenditures per beneficiary per month ( $\$ 858$ vs $\$ 888$ ) and fewer median emergency department visits (481 vs 518 ) and median acute care stays (282 vs 292) annualized per 1,000 beneficiaries compared to those for nonapplicant practices.

\section{CPC+ Participants vs Nonparticipants Among Applicants}

Differences between participant and nonparticipant applicant practices were small. Participants were more likely to be large, to have $\geq 1$ practitioner attest to meaningful use of EHRs, to be system-owned, to have transformation experience, and to serve slightly more advantaged beneficiaries than nonparticipating applicants (Tables 3 and 4).

\section{CPC+ Track 1 vs Track 2 Participants}

Among $\mathrm{CPC}+$ participating practices, Track 2 practices were larger than Track 1 practices (median number of practitioners 4 vs 3 ) and had more attributed Medicare beneficiaries (median 513 vs 453 ) but had fewer attributed Medicare beneficiaries per primary care practitioner (median 148 vs 170) (Supplemental Table 4). Track 2 practices were substantially more likely than Track 1 practices to have experience with primary care transformation efforts (78\% vs $53 \%)$. When considering TCPI and SSP as well, the proportions were closer $(88 \%$ for Track 2 vs $82 \%$ for Track 1). Track 2 practices were slightly more likely to have $\geq 1$ practitioner who had attested to meaningful use of EHRs than Track 1 practices (93\% vs $87 \%$ ). These differences were not surprising, given that Track 2 eligibility required more advanced care delivery approaches than Track 1 .

Track 2 practices were more likely to be located in an urban county than Track 1 practices (80\% vs 72\%) (Supplemental Table 4). The demographic and risk characteristics and the average expenditures and utilization of beneficiaries served by practices in the 2 tracks were very similar (most differences were not significant at the 5\% level) (Supplemental Table 5).

\section{DISCUSSION}

The CPC+ participation patterns analyzed in this study provide insights into the numbers and types of practices that might participate voluntarily in similar transformation models. Within the CPC+ regions, 15\% of all practices providing primary care to adults participated. The practices that applied to $\mathrm{CPC}+$, and that CMS then selected to participate, were diverse but not typical of the primary care practices in the CPC+ regions. They were generally more advanced (more likely to have had some experience with care transformation), had more resources (more likely to be larger and owned by a hospital or health system), served Medicare FFS beneficiaries that were slightly healthier and more advantaged, and were in counties with slightly greater median income than primary care practices that did not participate. The differences between practices that participated and those that applied but did not participate were similar but smaller.

These findings are in line with the study of practice participation by Fraze et al, who found that participating practices were more likely to be larger, to be owned by a hospital or health system, and to have a greater proportion of nonphysician clinicians compared with nonparticipating practices. ${ }^{2}$ Their study also found that practices in hospital service areas characterized by patient populations with greater advantage (greater median income, lesser share of households living in poverty, etc) were more likely to participate in $\mathrm{CPC}+$.

The diversity of $\mathrm{CPC}+$ practices, while not nationally representative, will enable CMS to draw lessons regarding barriers and facilitators to transformation and improved patient outcomes for the range of primary care practices that might participate in future models.

One implication of the present findings is that estimated impacts from CPC+ need to be extrapolated carefully to assess the implications of expanding it nationwide. This will be challenging. More advanced practices that are more likely to participate in such models might have the foundations needed and be better prepared to take advantage of the practice transformation supports provided to successfully adopt new delivery approaches. However, these practices might also have less room for improvement in care delivery approaches and patient outcomes. For example, in a study on early performance of Medicare SSP ACOs, McWilliams et al found that estimated savings were greater for ACOs that had baseline spending greater than local averages. ${ }^{4}$ Similarly, practices owned by a hospital or health system that are more likely to participate might have more resources to implement the care delivery changes required by these programs but might also have weaker incentives to lower spending (McWilliams et al found that independent physician groups were associated with savings in the Medicare SSP and that hospital-integrated ACOs did not produce savings). ${ }^{4}$

A second implication is that certain practices could be left behind if they are less likely to participate in pilot programs and if the tested care delivery and value-based payment models prove to have meaningful effects. More research to understand the reasons for the lower likelihood of participation of certain types 
of practices could enable policymakers to design outreach strategies and models that especially target these practices. Models that help a diverse set of providers transform how they deliver care and shift toward valuebased reimbursements might lessen the pressure that small and independent practices feel to join hospitalanchored systems that can provide more supports. ${ }^{5}$ Our finding that a slightly greater percentage of CPC+ Track 2 than Track 1 practices were owned by a hospital or health system (56\% vs $51 \%$ ) suggests that even within the same model, it might be possible to offer different packages of incentives and requirements to get a more diverse set of practices to participate. Finally, additional financial incentives for more disadvantaged patients could attract more practices that serve them.

This study has several limitations. Although we examined a diverse set of characteristics, there might be other differences between applicants and nonapplicants related to unobserved motivation and readiness for practice transformation. In addition, we focused on a single transformation program, $\mathrm{CPC}+$. Other models with a different set of payment incentives and model requirements are likely to attract different types of practices. Furthermore, we did not explore why participation rates differed across $\mathrm{CPC}+$ regions. We hope that the details of how we assembled our data set (described in the Methods section and the Supplemental Appendix) will motivate further research on participation patterns in other public and private transformation programs and, with respect to CPC+, an analysis of the role of geographic variation in payer penetration, expected payment levels, and distribution of practice characteristics in participation patterns.

To read or post commentaries in response to this article, see it online at https://www.AnnFamMed.org/content/18/4/309.
Key words: primary care; transformation; Comprehensive Primary Care Plus; primary care issues: patient-centered care; participation patterns

Submitted May 24, 2019; submitted, revised, November 27, 2019; accepted November 29, 2019.

Funding support: Supported by the Department of Health and Human Services, Centers for Medicare and Medicaid Services, under contract HHSM-500-2014-00034I/HHSM-500-T0010.

Disclaimer: The contents of this manuscript are solely the responsibility of the authors and do not necessarily represent the official views of the US Department of Health and Human Services or any of its agencies.

Clinical trial number: ClinicalTrials.gov Identifier: NCT03411785

Acknowledgments: The authors thank the Centers for Medicare and Medicaid Services CPC+ initiative program team and its contractors for sharing information and data. The authors also acknowledge the significant contributions to this study by Laura Blue, Carol Razafindrakoto, Nikkilyn Hensleigh, Edward Hoke, Lauryn Ringwood, Sera Gearhart, and Cindy George at Mathematica; Leah Hackleman-Good at Editorial Partners; and Timothy Day at the Centers for Medicare and Medicaid Services.

Supplemental materials: Available at https://www.AnnFamMed. org/content/18/4/309/suppl/DC1/.

\section{References}

1. Sessums LL, McHugh SJ, Rajkumar R. Medicare's vision for advanced primary care: new directions for care delivery and payment. JAMA. 2016;315(24):2665-2666.

2. Fraze TK, Fisher ES, Tomaino MR, Peck KA, Meara E. Comparison of populations served in hospital service areas with and without Comprehensive Primary Care Plus medical homes. JAMA Netw Open. 2018;1(5):e182169.

3. Cohen GR, Jones DJ, Heeringa J, et al. Leveraging diverse data sources to identify and describe U.S. health care delivery systems. EGEMS (Wash DC). 2017;5(3):9.

4. McWilliams JM, Hatfield LA, Chernew ME, Landon BE, Schwartz AL. Early performance of accountable care organizations in Medicare. N Engl J Med. 2016;374(24):2357-2366.

5. Berenson RA. A physician's perspective on vertical integration. Health Aff (Millwood). 2017;36(9):1585-1590. 